\title{
Influence du cytochrome P450 2D6 sur le métabolisme de la TFMPP (1-(3-trifluoro- méthylphenyl)pipérazine) : étude à l'aide de modèles in vitro et in vivo**
}

\begin{abstract}
Influence of cytochrome P450 $2 D 6$ on the metabolism of TFMPP (1-(3-trifluoro-methylphenyl)piperazine) : studies using in vitro and in vivo techniques $* *$
\end{abstract}

Roland F. STAACK, Lilane D. PAUL, Dietmar SPRINGER, Thomas KRAEMER, Hans H. MAURER*

Department of Experimental and Clinical Toxicology, University of Saarland D-66421 HOMBURG (SAAR) - GERMANY

*Auteur à qui adresser la correspondance : Prof. Dr. Hans H. MAURER, Department of Experimental and Clinical Toxicologyy, Institute of Experimental and Clinical Pharmacology and Toxicology, University of Saarland D-66421 HOMBURG (SAAR) - GERMANY - Tél : +49-6841-1626050 - Fax : +49-6841-1626051 E-mail : hans.maurer@uniklinik-saarland.de

** Ce travail a été présenté au XI $\mathrm{XI}^{\text {eme }}$ congrès de la Société Française de Toxicologie Analytique, 11-13 juin 2003, DINARD - FRANCE ** This work was presented orally at the $\mathrm{XI}^{\text {st }}$ congress of the French Society of Analytical Toxicology, 11-13 june 2003, DINARD - FRANCE

(Reçu le 22 octobre 2003 ; accepté le 22 décembre 2003) 


\section{$R E ́ S U M E ́$}

La connaissance des isoenzymes du cytochrome P450 (CYP), qui sont responsables du métabolisme des xénobiotiques, est indispensable pour prédire la toxicocinétique et l'évaluation des risques toxicologiques. La 1-(3-trifluoro-méthyl-phenyl)pipérazine (TFMPP) est une nouvelle drogue synthétique. Des études antérieures ont montré qu'elle est principalement metabolisée en hydroxy-TFMPP (OH-TFMPP). L'objet de cette étude a été de vérifier, à partir de modèles in vivo et in vitro, si cette réaction est catalysée par le cytochrome CYP2D6. dans ce travail, nous avons comparé le rapport TFMPP / OH-TFMPP dans l'urine de rats femelles Dark Agouti ( $f D A$, modèle du phénotype CYP2D6 métaboliseur lent), de rats Wistar (WI, modèle du phénotype CYP2D6 métaboliseur rapide) et de rats males Dark Agouti ( $\mathrm{mDA}$, modèle intermédiaire). Les résultats montrent clairement l'influence de cette enzyme. L'identification des CYP450 hépatiques humains a été réalisée in vitro à l'aide de microsomes hépatiques humaines et d'enzymes humaines recombinantes. Ces études ont montré que CYPIA2, CYP2D6 et CYP3A4 catalysent cette réaction, CYP2D6 étant l'enzyme la plus importante, responsable à $81 \%$ de la clairance hépatique. Des études d'inhibition ont confirmé ces résultats. La formation de métabolites était par ailleurs, significativement plus basse dans les microsomes des métaboliseurs lents. Les concentrations plasmatiques des différentes souches des rats ont été comparées pour vérifier si les pharmacocinétiques étaient différentes. Les rats WI avaient les concentrations les. plus faibles. Elles étaient déja plus élevées chez les rats $\mathrm{mDA}$ et de loin plus importantes chez les rats fDA.

\section{MOTS-CLÉS :}

1-(3-trifluoro-méthyl-phényl)pipérazine, TFMPP, métabolisme, cytochrome P450, rats Wistar, rats Dark Agouti.

\section{Introduction}

1-(3-trifluoromethylphenyl)piperazine (TFMPP) is a new designer drug of the class of piperazine-derived compounds, which was temporarily placed into Schedule I of the Controlled Substance Act in the United States of America (1). Its effects have been described to be similar to those of classical designer drugs (2). The involvement of particular cytochrome P450 (CYP) in the biotransformation of a new drug is needed for risk assessment. Previous in vivo studies in male Wistar rats (WI) showed that TFMPP was mainly metabolized by aromatic hydroxylation to hydroxy TFMPP (HO-TFMPP) (Figure 1) followed by partial glucuronidation or sulfatation (3). The first aim of the work presented here was to study, whether TFMPP hydroxylation may also be catalyzed by polymorphically expressed CYP2D6. For this purpose a rat model was used which has been proposed as a preliminary screening for CYP2D6 substrates $(4,5)$.

Female Dark Agouti rats (fDA) were chosen as a model of the human CYP2D6 poor metabolizer phenotype

\section{SUMMARY}

Knowledge of the cytochrome P450 (CYP) isoenzymes responsible for the metabolism of xenobiotics is indispensable for prediction of toxicokinetics and for risk assessment.

1-(3-trifluoro-methyl-phenyl)piperazine (TFMPP) is a new designer drug. Previous studies had shown that TFMPP was mainly metabolized by aromatic hydroxylation to hydroxy TFMPP (HO-TFMPP). In this study, in vivo and in vitro methods were used in order to investigate whether this reaction is catalyzed by CYP2D6. Therefore, the peak area ratios TFMPP/HO-TFMPP in urine of female Dark Agouti rats ( $f D A)$, a model of the human CYP2D6 poor metabolizer phenotype, male Dark Agouti rats (mDA), an intermediate model and Wistar rats (WI), a model of the human CYP2D6 extensive metabolizer phenotype, were compared. The results suggested the influence of CYP2D6. In vitro methods, different human hepatic microsomal preparations and recombinant human enzymes, were used in order to identify the human hepatic CYPs. These studies showed that CYPIA2, CYP2D6 and CYP3A4 catalyzed the monitored reaction, with CYP2D6 being the most important enzyme responsible for 81 \% of the net intrinsic clearance, which was confirmed by inhibition studies. Furthermore, metabolite formation was significantly lower in microsomes of a poor metabolizer. In order to study whether there are differences in the pharmacokinetic, blood plasma levels of the different rat strains were compared. WI showed the lowest blood levels, $f D A$ the highest and $m D A$ had blood levels on between.

\section{KEY-WORDS :}

1-(3-trifluoro-methyl-phenyl)piperazine, TFMPP, metabolism, cytochrome P450, Wistar rats, Dark Agouti rats.

(PM), WI as the corresponding model of the human CYP2D6 extensive metabolizer phenotype (EM) $(5,6)$ and male Dark Agouti rats (mDA) as an intermediate model between the PM and EM models (7). The second aim was to identify the human hepatic CYPs catalyzing TFMPP hydroxylation, to determine the kinetic constants for this reaction, to draw conclusions concerning the intrinsic clearances, and to compare the metabolite formation in pooled human liver microsomes (pHLM) and in single donor human liver microsomes with PM genotype (PM HLM). Finally, plasma levels in the above mentioned rats were compared in order to get hints for possible differences in pharmacokinetics in human PM and EM subjects relevant for risk assessment.

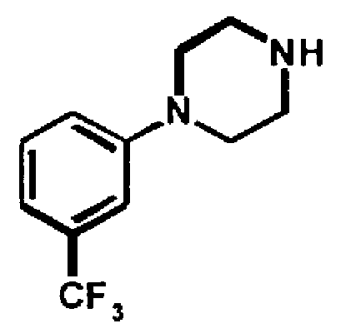

TFMPP

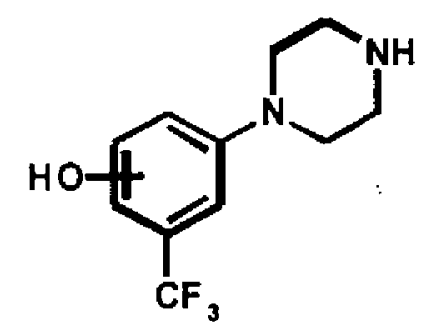

HO-TFMPP
Figure 1 : Structure of TFMPP and its major metabolite $\mathrm{HO}$ TFMPP. 


\section{Materials and Methods}

\section{Materials}

TFMPP-HCl and mCPP-HCl were obtained from Lancaster Synthesis, quinine and quinidine were obtained from Promochem, NADP $^{+}$was obtained from Biomol, isocitrate and isocitrate dehydrogenase from Sigma, all other chemicals and reagents from Merck. The following microsomes were from Gentest and delivered by NatuTec: baculovirus-infected insect cell microsomes containing $1 \mathrm{nmol} / \mathrm{ml}$ human cDNAexpressed CYP1A2, CYP2A6, CYP2B6, CYP2C8, CYP2C9, CYP2C19, CYP2D6, CYP2E1, or CYP3A4 (Supersomes), wild-type baculovirus-infected insect cell microsomes (control Supersomes), pHLM (20 mg microsomal protein/ml, $400 \mathrm{pmol}$ total $\mathrm{CYP} / \mathrm{mg}$ protein) and PM HLM (20 mg microsomal protein $/ \mathrm{ml})$. After delivery, the microsomes were thawed at $37^{\circ} \mathrm{C}$, aliquoted, snap-frozen in liquid nitrogen and stored at $-80^{\circ} \mathrm{C}$ until use.

\section{Animals, treatments and collection of urine and blood samples}

The rats were housed in metabolism cages for 24 hours, having water ad libitum The investigations have been performed as follows: urine samples $(n=8)$ were collected separately from the faeces over a $24 \mathrm{~h}$ period, blood samples $(n=4-6)$ were taken from the tail vein $1,3,5,7$, and 9 hours after administration of a single dose of TFMPP ( $20 \mathrm{mg} / \mathrm{kg}$ body mass, BM) in aqueous solution by gastric intubation. Furthermore, WI were pretreated with quinine $(80 \mathrm{mg} / \mathrm{kg} \mathrm{BM})$ (8) before administration of TFMPP ( $20 \mathrm{mg} / \mathrm{kg} \mathrm{BM})$ and blood samples were taken as described above. All samples were directly analyzed as described below.

\section{Sample preparation of rat urine and rat plasma samples}

The rat urine and blood plasma samples were prepared according to a validated procedure with modifications (9). The samples were extracted using mixed-mode HCX SPE cartridges and thereafter heptafluorobutyrylated. Details are described in ref. (10).

\section{Gas-chromatography-mass spectrome- try (GC-MS) analysis of rat urine and plasma samples}

The samples were analyzed using a Hewlett Packard (Agilent) HP 6890 Series GC system equipped with a HP-5MS capillary column ( $30 \mathrm{~m} \times 0.25 \mathrm{~mm}$ I.D.), combined with an HP 5972 Series mass selective detector, an HP 6890 Series injector and an HP Chem
Station G1701AA version A.03.00. Detailed information on the GC-MS conditions is given in ref.(10). In rat urine samples, the peak area ratios (PAR) between TFMPP and its metabolite HO-TFMPP were determined. In rat plasma samples the PAR between TFMPP and and $\mathrm{mCPP}$ (IS) were determined.

\section{Microsomal incubations}

The incubations were conducted at $37^{\circ} \mathrm{C}$. Typical incubation mixtures (final volume: $50 \mu \mathrm{l}$ ) consisted of 90 $\mathrm{mM}$ phosphate buffer ( $\mathrm{pH} 7.4$ ), $5 \mathrm{mM} \mathrm{Mg}^{2+}, 5 \mathrm{mM}$ isocitrate, $1.2 \mathrm{mM} \mathrm{NADP}+2 \mathrm{U} / \mathrm{ml}$ isocitrate dehydrogenase, $200 \mathrm{U} / \mathrm{ml}$ superoxide dismutase and substrate which was added after dilution of a $250 \mathrm{mM}$ methanolic stock solution in buffer. Reactions were started by addition of the ice-cold microsomes and terminated with $5 \mu l$ of $60 \%(w / w)$ perchloric acid, $1 \mu l$ of $0.5 \mathrm{mM}$ methanolic solution of mCPP was added as internal standard the incubation mixtures were centrifuged and the supernatants were transferred to autosampler vials.

\section{Initial screening studies}

In order to investigate the involvement of particular CYPs in TFMPP metabolism, $200 \mu \mathrm{M}$ TFMPP and 50 $\mathrm{pmol} / \mathrm{ml}$ CYP1A2, CYP2A6, CYP2B6, CYP2C8, CYP2C9, CYP2C19, CYP2D6, CYP2E1 or CYP3A4 were incubated for $30 \mathrm{~min}$. For incubations with CYP2A6 or CYP2C9, phosphate buffer was replaced with $45 \mathrm{mM}$ or $90 \mathrm{mM}$ Tris-buffer, according to the Gentest manuals.

\section{Enzyme kinetic studies}

Duration of and protein content for all incubations were in the linear range of metabolite formation (data not shown). Kinetic constants were derived from incubations ( $\mathrm{n}=2$ each) with the following TFMPP concentration ranges, incubation times and protein concentrations: $1-1500 \mu \mathrm{M}$ TFMPP with $50 \mathrm{pmol}$ CYP1A2/ml for $20 \mathrm{~min} ; 0.5-600 \mu \mathrm{M}$ TFMPP with 50 pmol CYP2D6/ml for $20 \mathrm{~min} ; 10-1300 \mu \mathrm{M}$ TFMPP with $80 \mathrm{pmol} \mathrm{CYP3A} 4 / \mathrm{ml}$ for $20 \mathrm{~min}$ and $1-1500 \mu \mathrm{M}$ TFMPP with $0.5 \mathrm{mg}$ pHLM protein $/ \mathrm{ml}$ for $20 \mathrm{~min}$. Less than $20 \%$ of substrate were metabolized in all incubations. Apparent $K_{m}$ and $V_{\text {max }}$ values for single isoforms were estimated by nonlinear regression according to the Michaelis-Menten equation. A two site binding model was applied to the data of the HLM experiments $(11,12)$. The kinetic data were estimated using GraphPad Prism 3.02 software (San Diego, CA).

Unfortunately, no reference substances of the metabolites were available. Therefore, only relative estimations of $V_{\max }$ values, expressed as dimensionless peak areas (PA) per minute and $\mathrm{mg}$ pHLM protein or pmol CYP for cDNA-expressed CYPs, could be obtained. 


\section{Calculation of relative activity factors and of intrinsic clearance}

Taking into account differences in functional levels of redox partners between the two enzyme sources, the relative activity factor (RAF) approach was used (13, 14). Reaction activities of probe substrates in both, insect cell microsomes and pHLM were taken from the supplier's data sheets. The RAFs and the percentage of intrinsic clearance by a particular isoform were calculated according to refs. $(11,13-16)$.

\section{Chemical inhibition studies}

The effect of $3 \mu \mathrm{M}$ quinidine on HO-TFMPP formation was assessed in incubations containing $0.5 \mathrm{mg}$ pHLM protein $/ \mathrm{ml}$ and $10 \mu \mathrm{M}$ TFMPP. Controls contained no quinidine, but the same amount of methanol to control for any solvent effects $(n=6$, each). Significance of inhibition was tested by a one-tailed unpaired t-test.

\section{Comparative studies between pHLM and PM HLM}

Incubations were carried out at $10 \mu \mathrm{M}$ TFMPP for 20 min using either $0.5 \mathrm{mg}$ pHLM or PM HLM protein $/ \mathrm{ml}$. Significance of differences in metabolite formation was tested by a one-tailed unpaired t-test.

\section{Liquid chromatography-mass spectro- metry (LC-MS) conditions and quantifi- cation in microsomal incubations}

TFMPP, HO-TFMPP and mCPP were separated and quantified using an Agilent Technologies AT 1100 series atmospheric pressure chemical ionization (APCI) LC-MSD, SL version and a LC-MSD ChemStation using the A.08.03 software. Gradient elution was performed. The mobile phase consisted of ammonium formate $(5 \mathrm{mM}$, adjusted to $\mathrm{pH} 3.0$ with formic acid; eluent A) and acetonitrile (eluent B). Detailed information on the gradient, the flow rate, the APCI and MS conditions is given in ref. (10).

\section{Results}

\section{Analysis of rat urine samples}

In rat urine samples, the PAR of TFMPP vs. HOTFMPP was determined (given values are the mean of the results of eight analyses \pm standard error of the mean). The lowest ratio was determined in urine of WI (PAR TFMPP vs. HO-TFMPP: $0.08 \pm 0.04$ ) and the highest in urine of fDA (PAR TFMPP vs. HO-TFMPP: $3.48 \pm 0.76$ ). The ratio determined in urine of $\mathrm{mDA}$ lay between these two groups (PAR TFMPP vs. HOTFMPP: $0.54 \pm 0.18$ ). The means of metabolic ratios of the three rat groups were significantly different among each other (comparison in pairs, $\mathrm{p}<0.0001$ ).

\section{LC-MS procedures}

The applied LC-MS conditions provided baseline separation of HO-TFMPP, mCPP and TFMPP. The chosen target ions were selective for the analytes under these conditions as proven with blank samples (control microsomes without substrate and IS) and zero samples (control microsomes without substrate, but with IS; data not shown).

\section{Initial screening studies}

Among the nine CYPs tested only CYP1A2, CYP2D6 and CYP3A4 catalyzed the hydroxylation of TFMPP. HO-TFMPP was not detectable in incubations with the remaining cDNA-expressed CYPs or with insect cell control microsomes.

\section{Kinetic Studies}

All incubations were carried out at initial rate conditions, a prerequisite for Michaelis-Menten kinetics (17). All of the kinetics with single cDNA-expressed CYPs showed a typical hyperbolic profile and the kinetic parameters are shown in Table I.

$V_{\text {max }}$ values could only be expressed as arbitrary units, because the metabolites could not be quantified without reference substances. The $\mathrm{V}_{\max }$ values are expressed as dimensionless PA per min and pmol CYP for cDNAexpressed CYPs or as PA per min and mg microsomal protein for HLM.

Calculation of the percentage of the different CYP isoforms to the predicted total TFMPP hydroxylation clearance by all individual CYPs in liver microsomes showed that CYP2D6 was the major isoform which catalyzed the monitored reaction. CYP2D6 accounted for $81 \%$ of predicted total TFMPP hydroxylation clearance. CYP1A2 and CYP3A4 were responsible for only about $10 \%$ each. More details are given in (10).

Table I : Kinetic data of TFMPP hydroxylation by CYP1A2, CYP2D6, CYP3A4 and $p H L M$.

\begin{tabular}{|lcccc|}
\hline & CYP1A2 & CYP2D6 & CYP3A4 & pHLM $^{\mathrm{a}}$ \\
\hline $\begin{array}{l}\text { Apparent } \mathrm{K}_{\mathrm{m}} \\
{[\mu \mathrm{M}]}\end{array}$ & $186.2 \pm 32.3$ & $7.8 \pm 1.8$ & $487.7 \pm 98.9$ & $11.2 \pm 11.6$ \\
$\left.\begin{array}{l}\text { Vmax } \\
{\left[\min ^{-1 *} \text { pmol CYP-1] or }\right.} \\
{\left[\text { minn }^{-1 *} \text { mg HLM }\right.}\end{array}\right]$ & $2.3 \pm 0.1$ & $8.0 \pm 0.4$ & $1.5 \pm 0.1$ & $60.7 \pm 20.9$ \\
\hline
\end{tabular}

${ }^{a}$ Kinetic data estimated according to a two site binding. 


\section{Chemical inhibition studies}

In order to underline the importance of CYP2D6 in TFMPP hydroxylation, the CYP2D6 specific inhibitor quinidine $(3 \mu \mathrm{M})$ was added to incubation mixtures and the metabolite formation rate compared with incubations without inhibitor. In presence of inhibitor and $10 \mu \mathrm{M}$ TFMPP the metabolite formation was significantly inhibited by about $78 \%(\mathrm{p}<0.0001)$.

\section{Comparative studies between pHLM and PM HLM}

In order to further underline the importance of CYP2D6 in TFMPP hydroxylation and to demonstrate differences in PM and EM subjects, the metabolite formation rate of pHLM was compared to that of PM HLM. The metabolite formation rate of PM HLM was about $63 \%$ lower $(p<0.0001)$ than that of pHLM.

\section{Analysis of rat plasma samples}

In rat plasma samples, the PARs of TFMPP vs. mCPP were determined. As shown in Table. II, the blood plasma levels in fDA were significantly higher than those of WI ( $p \leq 0.0013)$ and of $\mathrm{mDA}(\mathrm{p} \leq 0.0164)$. The blood plasma levels in mDA always lay in between fDA and WI and were always significantly higher than those of WI ( $p \leq 0.004)$. Pretreatment of WI with quinine led to significantly higher blood plasma levels at all time points ( $p \leq 0.01$ ) compared to untreated WI.

Table II : Peak area ratios (PAR) of TFMPP/mCPP (IS) determined in blood plasma, after solid phase extraction and heptafluorobutyrylation, of fDA, $m D A$, and WI as well as of WI after pretreatment with $80 \mathrm{mg} / \mathrm{kg}$ BM of quinine taken $\mathrm{I}$, $3,5,7$, and 9 hours after administration. Each value represents the mean of four samples \pm standard error of the mean.

\begin{tabular}{|ccccccc|}
\hline & $1 \mathrm{~h}$ & $3 \mathrm{~h}$ & $5 \mathrm{~h}$ & $7 \mathrm{~h}$ & $9 \mathrm{~h}$ \\
\hline $\mathrm{fDA}$ & $0.66 \pm 0.04$ & $1.16 \pm 0.27$ & $1.437 \pm 0.15$ & $1.56 \pm 0.19$ & $0.85 \pm 0.15$ \\
$\mathrm{mDa}$ & $0.26 \pm 0.07$ & $0.53 \pm 0.02$ & $0.41 \pm 0.01$ & $0.17 \pm 0.01$ & $0.07 \pm>0.01$ \\
WI & $0.15 \pm 0.01$ & $0.22 \pm 0.02$ & $0.19 \pm 0.01$ & $0.08 \pm>0.01$ & $0.04 \pm>0.01$ \\
WI (pretreated) & $0.31 \pm 0.04$ & $0.53 \pm 0.10$ & $0.79 \pm 0.19$ & $0.73 \pm 0.09$ & $0.52 \pm 0.11$ \\
\hline
\end{tabular}

\section{Discussion}

Metabolism studies of new designer drugs are commonly conducted using rat models, due to ethical reservation about human studies $(3,18-21)$. In the current study, it was examined whether TFMPP hydroxylation may be catalyzed by CYP2D6 by comparing PAR of TFMPP vs. HO-TFMPP in urine from $\mathrm{FDA}, \mathrm{mDA}$ and WI. These animals were proposed as a model allowing a preliminary screening for CYP2D6 substrates. The results showed that WI (EM model) excreted TFMPP mainly as the corresponding hydroxy metabolite, mDA (intermediate model) excreted TFMPP significantly less metabolized, with HO-TFMPP still being the main analyte and fDA (PM model) mainly excreted the unmetabolized parent compound TFMPP. These results suggested that TFMPP hydroxylation should be catalyzed by CYP2D6 in humans.

For confirmation, the human hepatic CYPs involved in TFMPP hydroxylation were identified using microsomal preparations from different sources. This method has already been described for other new designer drugs $(11 ; 16)$. According to the supplier's advice, the incubation conditions chosen were adequate to make a statement on a general involvement of a particular CYP isoform. Among the nine CYP isoforms tested only CYP1A2, CYP2D6 and CYP3A4 supported the hydroxylation of TFMPP.

The kinetic profiles of the reactions by these particular CYPs and pHLM were further investigated. As no reference substance of the monitored metabolite was available for its exact quantification, only PAs could be determined instead of absolute metabolite concentrations. However, this neither affected the conclusions drawn from the kinetic estimations, nor those from the inhibition studies. Linearity of the mass spectrometer response over the concentration range could be shown for structurally closely related compounds (data not shown), so that linearity of the mass spectrometer response of HO-TFMPP could be assumed.

As expected, classical hyperbolic Michaelis-Menten plots were found using cDNA-expressed CYPs. The apparent $\mathrm{Km}$ and $V \max$ values of the investigated CYPs were calculated by nonlinear regression fit according to the Michaelis-Menten equation. As more than one enzyme was involved in TFMPP hydroxylation, a two site binding model was applied to the data of the HLM experiments.

The RAF approach $(11,13,14,16,22,23)$ was used to correct recombinant CYP formation rates for native human liver enzyme activity and revealed that CYP2D6 accounted for $81 \%$ of predicted total TFMPP hydroxylation clearance by all individual CYPs in pHLMs. CYP1A2 and CYP3A4 were responsible for only about $10 \%$ each.

In order to confirm the role of CYP2D6 in TFMPP hydroxylation, inhibition studies with the CYP2D6 specific chemical inhibitor quinidine (6) were performed at a substrate concentration corresponding to the calculated $\mathrm{Km}, 1$ value in $\mathrm{pHLM}$. The concentration of the inhibitor $(3 \mu \mathrm{M})$ was based on average literature data $(11,16,17,24,25)$. The results showed that the overall turnover was significantly inhibited by about 
$77 \%$, which was consistent with the observation, that CYP2D6 accounted for about $81 \%$ of the net intrinsic clearance of TFMPP. Comparative studies using PHLM and PM HLM revealed significant differences between CYP2D6 PM and EM, with PM HLM showing $63 \%$ lower metabolite formation rate.

In order to find out whether TFMPP plasma levels vary in PM and EM possibly resulting in different toxicological risks plasma levels in the described rat models were examined. The deficiency of fDA of hydroxylating TFMPP should led to increased blood plasma levels of the parent compound. In fact, fDA showed the highest and WI showed the lowest TFMPP blood plasma levels at all sample times and the plasma levels in mDA lay between these two groups. Pretreatment of WI with the the CYP2D specific inhibitor quinine $(6$, 26) resulted in significantly higher TFMPP plasma levels, a further confirmation that the differences could be attributed to the differences in CYP2D activity. In summary, the studies showed that TFMPP hydroxylation is mainly catalyzed by CYP2D6. The animal studies indicated that CYP2D6 PM might exhibit a lower clearance than EM. Furthermore, simultaneous intake of potent CYP2D6 inhibitory drugs might also lead to a decreased clearance of TFMPP and, consequently, lead to elevated plasma concentrations. Whether this genetic polymorphism and/or drug interactions are of relevance for TFMPP pharmacokinetics and/or clinical outcome of intoxications, cannot be assessed at the moment due to lack of sufficient authentic human data.

\section{Acknowledgements}

The authors would like to thank Gabi Ulrich, Thomas Pflugmann, Frank T. Peters, Carsten Kratzsch and Armin A. Weber for their assistance and helpful discussions.

\section{Références}

1. Drug Enforcement Administration - Department of Justice Schedules of controlled substances: temporary placement of benzylpiperazine and trifluoromethylphenylpiperazine into schedule I. Fed. Register $2002 ; 67$ : 59161-2.

2. Murphy D. L., Lesch, K. P., Aulakh, C. S., Pigott, T. A. Serotonin-selective arylpiperazines with neuroendocrine, behavioral, temperature, and cardiovascular effects in humans. Pharmacol. Rev. 1991 ; 43 : 527-52.

3. Staack R. F., Fritschi, G., Maurer, H. H. New designer drug 1-(3-trifluoromethylphenyl)piperazine (TFMPP): gas chromatography/mass spectrometry and liquid chromatography/mass spectrometry studies on its phase I and II metabolism and on its toxicological detection in rat urine. J. Mass Spectrom. 2003 ; $38: 971-81$.

4. Barham H. M., Lennard, M. S., Tucker, G. T. An evaluation of cytochrome $\mathrm{P} 450$ isoform activities in the female dark agouti (DA) rat: relevance to its use as a model of the CYP2D6 poor metaboliser phenotype. Biochem. Pharmacol. $1994 ; 47$ : 1295-307.

5. Schulz-Utermoehl T., Bennett, A. J., Ellis, S. W., Tucker, G. T., Boobis, A. R., Edwards, R. J. Polymorphic debrisoquine 4-hydroxylase activity in the rat is due to differences in CYP2D2 expression. Pharmacogenetics 1999 ; $9: 357-66$.

6. Kobayashi S., Murray, S., Watson, D., Sesardic, D., Davies, D. S., Boobis, A. R. The specificity of inhibition of debrisoquine 4-hydroxylase activity by quinidine and quinine in the rat is the inverse of that in man. Biochem. Pharmacol. $1989 ; 38: 2795-99$.

7. Vorhees C. V., Morford, L. L., Inman, S. L., Reed, T. M., Schilling, M. A., Cappon, G. D., Moran, M. S., Nebert, D. W. Genetic differences in spatial learning between Dark Agouti and Sprague- Dawley strains: possible cor- relation with the CYP2D2 polymorphism in rats treated neonatally with methamphetamine. Pharmacogenetics $1999 ; 9: 171-81$.

8. Law M. Y., Slawson, M. H., Moody, D. E. Selective involvement of cytochrome $\mathrm{P} 4502 \mathrm{D}$ subfamily in in vivo 4-hydroxylation of amphetamine in rat. Drug Metab. Dispos. $2000 ; 28: 348-53$.

9. Peters F. T., Schaefer, S., Staack, R. F., Kraemer, T., Maurer, H. H. Screening for and validated quantification of amphetamines and of amphetamine- and piperazinederived designer drugs in human blood plasma by gas chromatography/mass spectrometry. J. Mass Spectrom. $2003 ; 38: 659-76$.

10. Staack R. F., Paul, L. D., Springer, D., Kraemer, T., Maurer, H. H. Cytochrome P450 dependent metabolism of the new designer drug 1-(3-trifluoromethylphenyl)piperazine (TFMPP). In vivo studies in Wistar and Dark Agouti rats as well as in vitro studies in human liver microsomes. Biochem. Pharmacol. 2004, $67: 235-44$.

11. Springer D., Paul, L. D., Staack, R. F., Kraemer, T., Maurer, H. H. Identification of the cytochrome P450 enzymes involved in the metabolism of 4'-methyl(alpha)-pyrrolidinopropiophenone, a novel scheduled designer drug, in human liver microsomes. Drug Metab. Dispos. $2003 ; 31: 979-82$.

12. Korzekwa K. R., Krishnamachary, N., Shou, M., Ogai, A., Parise, R. A., Rettie, A. E., Gonzalez, F. J., Tracy, T. $S$. Evaluation of atypical cytochrome P450 kinetics with two-substrate models : evidence that multiple substrates can simultaneously bind to cytochrome P450 active sites. Biochemistry $1998 ; 37: 4137-47$.

13. Crespi C. L. and Miller, V. P. The use of heterologously expressed drug metabolizing enzymes-state of the art and 
prospects for the future. Pharmacol. Ther. $1999 ; 84$ : 121-31.

14. Venkatakrishnan K., von Moltke, L. L., Court MH, Harmatz, J. S., Crespi, C. L., Greenblatt, D. J. Comparison between cytochrome P450 (CYP) content and relative activity approaches to scaling from cDNAexpressed CYPs to human liver microsomes: ratios of accessory proteins as sources of discrepancies between the approaches. Drug Metab. Dispos. 2000 ; 28 : 1493504.

15. Stormer E., von Moltke, L. L., Greenblatt, D. J. Scaling drug biotransformation data from cDNA-expressed cytochrome P-450 to human liver: a comparison of relative activity factors and human liver abundance in studies of mirtazapine metabolism. J. Pharmacol. Exp. Ther. 2000 ; $295: 793-801$.

16. Springer D., Staack, R. F., Paul, L. D., Kraemer, T., Maurer, H. H. Identification of cytochrome P450 enzymes involved in the metabolism of 4'-methoxy-pyrrolidinopropiophenone (MOPPP), a designer drug, in human liver microsomes. Xenobiotica 2003 ; 33 : 989-98.

17. Clarke S. E. In vitro assessment of human cytochrome P450. Xenobiotica $1998 ; 28: 1167-202$.

18. Kanamori T., Inoue, H., Iwata, Y., Ohmae, Y., Kishi, T. In vivo metabolism of 4-bromo-2,5-dimethoxyphenethylamine (2C-B) in the rat: identification of urinary metabolites. J. Anal. Toxicol. 2002 ; 26 : 61-66.

19. Staack R. F., Fritschi, G., Maurer, H. H. Studies on the metabolism and the toxicological analysis of the new piperazine-like designer drug $\mathrm{N}$-benzylpiperazine in urine using gas chromatography-mass spectrometry. $\mathbf{J}$. Chromatogr. B $2002 ; 773: 35-46$.
20.Staack R. F., Fehn, J., Maurer, H. H. New designer drug para-methoxymethamphetamine: Studies on its metabolism and toxicological detection in urine using gas chromatography-mass spectrometry. J. Chromatogr. B 2003 ; $789: 27-41$.

21. Staack R, F, and Maurer, H. H. Piperazine-derived designer drug 1-(3-chlorophenyl)piperazine (mCPP): GCMS studies on its metabolism and its toxicological detection in urine including analytical differentiation from its precursor drugs trazodone and nefazodone. J. Anal. Toxicol. $2003 ; 27: 560-568$.

22. Crespi, C. L. (1995) (Testa, B. and Meyer, U. A., Eds.) pp 179-235, Academic Press, London.

23. Crespi C. L. and Penman, B. W. Use of cDNA-expressed human cytochrome P450 enzymes to study potential drug-drug interactions. Adv. Pharmacol. $1997 ; 43$ : 17188.

24. Rotzinger S., Fang, J., Coutts, R. T., Baker, G. B. Human CYP2D6 and metabolism of $\mathrm{m}$-chlorophenylpiperazine. Biol. Psychiatry $1998 ; 44: 1185-91$.

25. von-Moltke L. L., Greenblatt, D. J., Granda, B. W., Grassi, J. M., Schmider, J., Harmatz, J. S., Shader, R. I. Nefazodone, meta-chlorophenylpiperazine, and their metabolites in vitro: cytochromes mediating transformation, and P450-3A4 inhibitory actions. Psychopharmacology Berl. 1999 ; 145 : 113-22.

26. Moody D. E., Ruangyuttikarn, W., Law, M. Y. Quinidine inhibits in vivo metabolism of amphetamine in rats: impact upon correlation between GC/MS and immunoassay findings in rat urine. J. Anal. Toxicol. $1990 ; 14: 311$ 17. 